\title{
Experimental Allergic Encephalomyelitis
}

National Cancer Institute

\section{Source}

National Cancer Institute. Experimental Allergic Encephalomyelitis. NCI Thesaurus. Code C3006.

An autoimmune demyelinating disease of the central nervous system that is produced experimentally in animals by the injection of homogenized brain or spinal cord in Freund's adjuvant. Myelin basic protein appears to be the antigen that elicits the hypersensitivity immune response which is characterized by focal areas of lymphocyte and macrophage infiltration into the brain, associated with demyelination and destruction of the bloodbrain barrier. Experimental allergic encephalomyelitis (EAE) is used as an animal model for demyelinating diseases of the human central nervous system such as multiple sclerosis. 